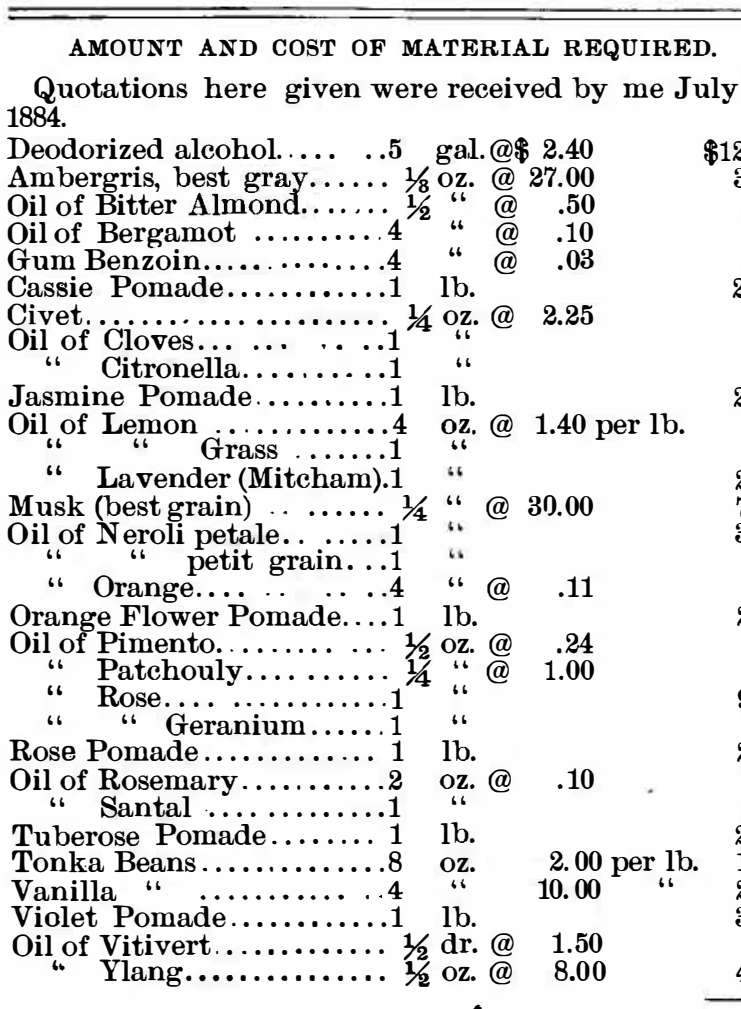

1. AMBERGRIS EXTRACT.

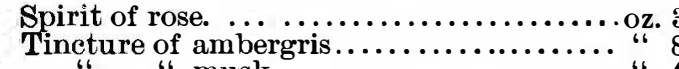
" " " vanilla......................... " Cost $\$ 6.07$ per pint. Where permanence is desired,
this can be recommended.

Tincture of ambergris.

Essence of cassie.

" neroli petale. Cost $\$ 2.18$. ESS. BOUQUET.

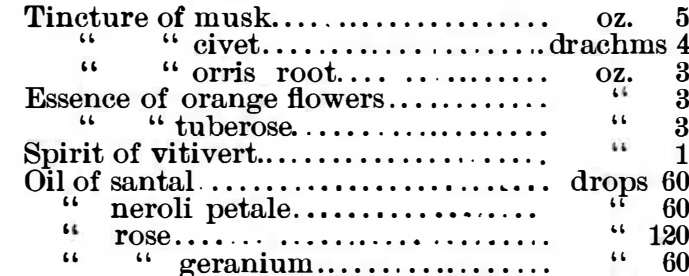

Cost $\$ 6.50$ per pint. Where there is a demand for something lasting, regardless of price, this will prove satisfactory.

ROSE GERANIUM EXTRACT.

Oil of rose geranium.................. oz. 1

HELIOTROPE.

5

Tincture of vanilla.

$$
\text { " " ambergris. }
$$

Spirit of rose.

Oil of bitter almond...

Oil of bitter almond.
Cost $\$ 2.10$ per pint.

6.

$$
\text { HONETSUCKLE. }
$$

Essence of rose...................... oz. 4

Tincture of vanilla...

" " $"$ tolu......

Oil of neroli petale $\ldots \ldots \ldots \ldots \ldots \ldots \ldots \ldots$ "

" bitter almond......................

Cost $\$ 2.80$ per pint.

7. JOCKEY CLUB.

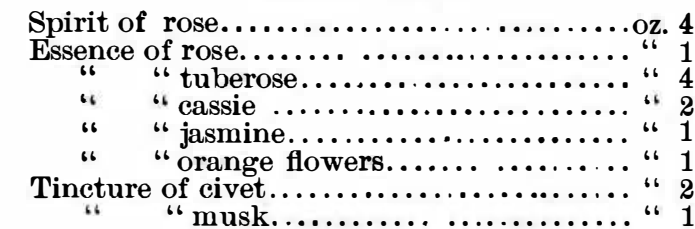

Cost $\$ 2.50$ per pint.

$8 . \quad$ LAVENDER EXTRACT.

Oil of lavender (Mitcham) .........drachms 4

Essence of rose.................... on ${ }_{14}^{2}$

Cost $\$ 2.30$ per pint. By using the common oil of lay

Cost $\$ 2.30$ per pint. By using the comm
ender flowers the cost will be about $\$ 1.20$.

9. LILY of the VALLeY oR white POND LILY.

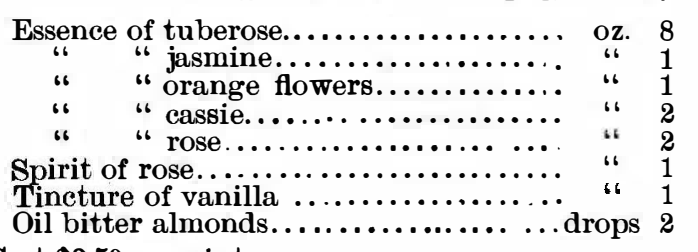

Oincture of vaniter almonds.

Cost $\$ 2.50$ per pint.
10. MILlEFLEURS (THOUSAND FLOWERS). Spirit of rose......

"Essence of rose........

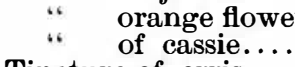

Tincture of orris.

"، " " ambergris...................

Oil bitter almonds....

" of neroli petale................ drops

Cost $\$ 2.55$ per pint.

11.

Tincture of musk..........

MUSK.

Spirit of rose usk

Tincture of civet

article but the tincture of musk rather a high priced

half with alcohol and still yield a satisfactory result

9.00 The cost will then be $\$ 3.25$.
.00

2.5012 .

NEW MOWN HAY.

Tincture of tonka................. oz. 6

Spirit of rose...

Oil of neroli petale $\ldots \ldots \ldots \ldots \ldots \ldots \ldots \ldots . .6$ drops 10

Deodorized alcohol................... oz ${ }^{4}$

Cost $\$ 1.65$ per pint.

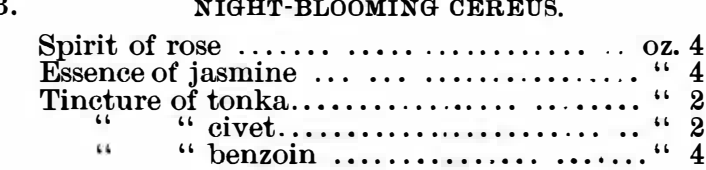

Cost $\$ 1.65$ per pint.

ORANGE FLOWER EXTRACT

Essence of orange flowers.............. oz. 12

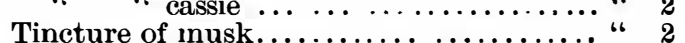

Cost $\$ 3.20$ per pint.

15. Patchouly.

Oil of patchouly .................. drops 75

Deodorized alcohol..................... oz. 16 Cost 75 cents per pint

16. SWEET PEA.

Essence of tuberose $\ldots \ldots \ldots \ldots \ldots \ldots \ldots \ldots \ldots$
"،

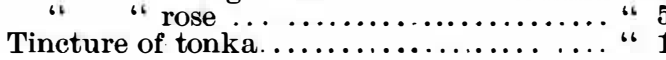

Cost $\$ 2.50$ per pint.

17.

Essence of CLOVE PINK.

Spirit orange flower

Tincture of vanilla................... Cost $\$ 2.40$ per pint.

$18 . \quad$ RONDOLETIA

Tincture of musk...............drachms 4

" " vanilla

Oil of bergamot..........

"، cloves ...................... " "

Deodorized alcohol.................... drops oz. ${ }_{14}^{30}$ Cost $\$ 2$ per pint. With common oil of lavend
flowers it will cost $\$ 1.60$.

19.

ROSE

White Rose (No. 1)

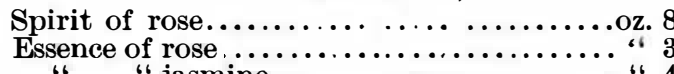

Extract of patchouly........................ ، 1

Cost $\$ 2.50$ per pint.

$20 . \quad$ White Rose (No. 2).

Oil of rose........................ drachms 2

Essence of rose.

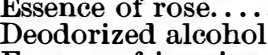

Essence of jasmin

Cost " $\$ 3$ per pint ambergris............ " 1 Cost $\$ 3$ per pint. Extract of white rose is a gen
favorite, and cannot be recommended too highly.

21 .

Spirit of rose..............................

" " rose........................... "

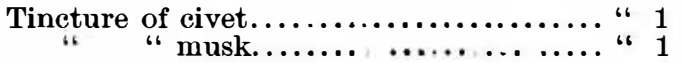

Cost $\$ 2.85$ per pint

22. TEA ROSE

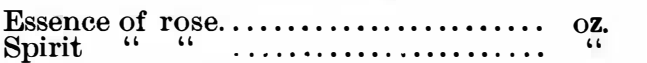

Essence of orange flower....

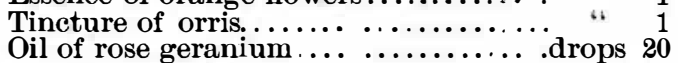
Cost $\$ 2.20$ per pint.

23. SPRING FLOWERS.

Essence of rose. .

Oil of bergamot.

Spirit of rose ....................

Essence of cassie
24. TUBEROSE EXTRACT.

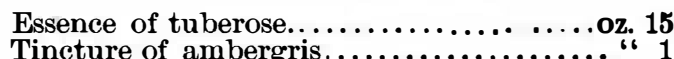
Cost $\$ 2.85$ per pint.

25. UPPER TEN.

Tincture of vanilla........

(4) 4

Spirit of "orre........

Essence of orange flowers...............
Oil of bergamot.

Cost $\$ 2.75$ per pint.

26.

VERBENA

Oil of lemon grass .................drops 50

". lemon ........

" neroli petale...

Essence of orange flowers

Spirit of rose............

Cost $\$ 1.90$ per pint.

27. VERBena (No. 2).

Oil of lemon grass ................ drachms 3

" orange $\ldots \ldots \ldots \ldots \ldots \ldots \ldots \ldots$ drops $\begin{array}{r}30 \\ 30\end{array}$

Cost 60 cents per pint.

28. VIOLE'T.

Essence of violets. .....................

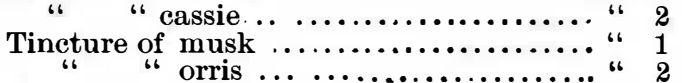
Cost $\$ 3$ per pint.

$29 . \quad$ viOLET (No. 2).

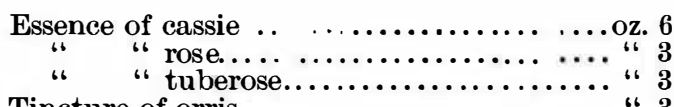

Tincture of orris $\ldots \ldots \ldots \ldots \ldots \ldots \ldots \ldots \ldots \ldots$ on 3

Cost $\$ 2.05$ per pint.

$30 . \quad$ WOOD VIOLET.

Extract of violets, No. $2 \ldots \ldots \ldots \ldots \ldots$ oz. 16
Oil of bitter almonds................drops 15 Cost $\$ 2.10$ per pint.

31.

Spirit of ylang YLANG YLANG.

"Essence of jasinine

Cost $\$ 2.70$ per pint. This is my favorite; it combines

32. WHITE LILAC

Essence of tuberose. ............ oz. 12

Tincture of civet..................... drachms 3

Spirit of ylang $\ldots \ldots \ldots \ldots \ldots \ldots \ldots$
Oil of bitter almonds ............... drops $\quad 3$

Cost $\$ 2.50$ per pint.

To thoise who may wish to carry their study in perfumes and kindred arts further, I can recommend the Snively, and W. Saunders' article on perfumes read at American Pharmaceutical Association.

ON THE BOILING-POINT OF HYDROGEN.

By EdMund J. MiLls, D.Sc., F. R.S.

IN a recent memoir (Phil. Mag., [5] xvii., 173) I showed that the boiling-point $y$ of any member of a homologous series is related as follows to the coefficient $x$ o

$$
y=\frac{\beta(x-c)}{1+\gamma(x-c)}
$$

$c$ being the value of $x$ to which zero Centigrade corresponds, and $\beta \gamma$ constants depending on pressure and
other conditions. Thus, the equation to the series of other conditions. Thus, the equar
olefines in which $x$ is even is-

$$
y=\frac{40 \cdot 709(x-4 \cdot 228)}{1+0 \cdot 060123(x-4 \cdot 228)}
$$

Putting $x=2, y=-1047^{\circ}$, the calculated boilingpoint, at the ordinary pressure, of common olefiant gas. that olefiant gas boils at $-103^{\circ}$ under a pressure of 750 mit The satisfactory character of this result has induced me to calculate the boiling-point of hydrogen. It is
perfectly clear, and has been long since supposed, that 列 of paraffins, C $\mathrm{H}_{2 n+2}$. In the memoir referred to the boiling-points of the normal paraffins were discussed,
and equations found for them. There are in all four
series to deal with, viz, the even and odd series under series to deal with, viz., the even and odd series under ordinary pressure, and the same series under a pressure
of $15 \mathrm{~mm}$., the latter having been worked out by

The equation for the even series is$y=\frac{39.315(x-3.94)}{1+0.070753(x-3.94)} ;$

and for the odd series-

$$
y=\frac{38.992(x-3.92)}{1+0.070564(x-3.92)} .
$$

Under $15 \mathrm{~mm}$., the equation to the even series is-

$$
y=\frac{23 \cdot 154(x-7 \cdot 1)}{1+0 \cdot 035484(x-7 \cdot 1)}
$$

and to the odd series-

$y=\quad 21 \cdot 685(x-6 \cdot 77)$

$y=\begin{array}{r}21 \cdot 685(x-6 \cdot 77) \\ 1+0.030437(x-6.77)\end{array}$ 
When in each of these four equations we put $x=0$

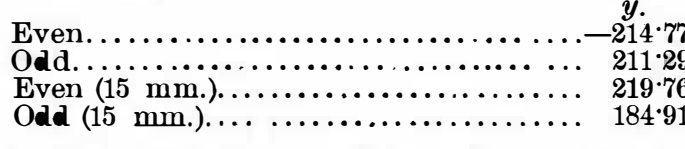

The discordance between the results for the odd series, as compared with those of the even series, shows ries of paraffins. The tworesults, however, for the even
series amply support each other, and show the boilingpoint of hydrogen to be about $-215^{\circ}$

Messrs. Wroblewski and Olzewski are understood to ject According tothe former (Comptes Rendus, xcviii. 982, oxygen and nitrogen boil respectively at $-184^{\circ}$ and $-193^{\circ}$ under the ordinary pressure, and the temperafrom $-184^{\circ}$. These temperatures were measured thermoelectrically. Olzewski, who uses a hydrogen thermo
meter, has also liquefied hydrogen, and alleges that he
has measured a temperature of $-213^{\circ} \mathrm{C}$. (Ibid., xcix. 134 .

The question will probably be settled at an early date to differ greatly from $-215^{\circ}$ C.-Chemical News.

\section{NEUMAYER'S TELEPHONE.}

In the central telephone office at Murich the Ader transmitter is employed, and the receivers are those of in the annexed figure. The magnet consists of five small bars, $m$, made of the best quality of English steel sible in the pole facing the vibrating disk, Mr. Neumayer employs a bundle of extremely fine wire, $e$ and the lower half is intimately connected with ma netized rods, $m$. 'The other half serves as a support fo a resistance in general of $100 \mathrm{ohms}$.

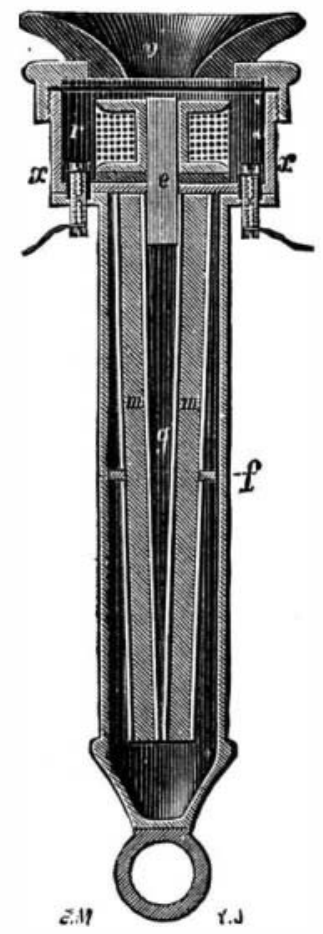

NEUMAYER'S TELEPHONE.

In order to prevent those variations in distance between the diaphragm and polewhichare a consequence of variations in temperature, the brass plate soldered
to the bundle, $e$, is serewed to the box, $x$, that carries to the bundle, $e$, is screwed to the box, $x$, that carries
the vibrating disk. This box is of brass, and the diaphragm, which is $0.3 \mathrm{~mm}$. in thickness, rests upon the top of it. The magnetized bars, $m$, are held in a brass ring, $f$, which is provided with a corresponding number of recesses.-La Lumiere Electrique.

ELECTRICITY'S DEADLY WORK.

A SHOCKING tragedy occurred on Sunday night in been erected for the festival of All Saints' and All Souls' Days. It was a case of peculiar interest. A man known as Pantaleon Estrada, a worker in guitars, tying a stone to the end of an ordinary wire, threw it A policeman standing by and a street car conductor selves so seriously injured that their lives tremble in the balance. The electric current affected others also
more or less. The scene succeeding the traged was more or less. The scene succeeding the tragedy was ing strong men totter and fall, as if struck by some inthe terrorized apathy came a wild rush for life. For fact that many were not stamped to death.

a ladder, with a silk hand lerehief in hamp mounted a ladder, with a silk handkerchief in hand, to remove the wire thrown by the unfortunate Estrada. The
rain was falling heavily at the time, but he did not notice that the handkerchief was becoming damp. He applied it to the wire to remove it, and received himFalling to the stone pavement his head was cut open. trada represents a gang of pickpockets and thieves the electric lights and give his pals a chance to operat Whether that was so or not is not known, for he who

\section{ELECTRICITY AS A MOTOR.}

Prof. Moses G. Farmer, in a recent letter to Mr. .W. Field, gives the following interesting historical Now that the application of electricity to the elevated roads is agitated, it occurs to me that it may be interesting to glance at some of the steps in the pro-
gress of discovery and invention which made electrogress of discovery and invention which made electroIt was not until 1819-20 that Oersted, of Copenhagen, discovered that, if a wire carried a current of electricity from south to north over a magnetic needle, it caused
the north end of the needle to be deflected toward the west, and also, if the current passed from north to south under the needle, the deflection of the north end
of the needle was still toward the west. It was not long before Schweiger carried the wire and current several times over and under the needle, and thus invented the galvanometer. Before 1826 Sturgeon had wound a wire several times around a bar of scft iron, and, when a current of electricity was sent magnet of the iron bar, which magnetism remained as
mand ong as the current was flowing. Soon after, as early as 1831, Faraday discovered the principal facts of magelectric machine possible in the hands of Pixii in 1832. The Daniell's and the Grove's batteries soon after appeared, and in 1839 Jacobi, at St. Petersburg, con-
structed a boat, which he propelled upon the River
Neva with a two horse-power electro-magnetic engine, Neva with a two horse-power electro-magnetic engine,
actuated by a Grove battery, which had in it twenty actuated by a Grove battery, whice

In 1840 Davenport and Cook, of Vermont, constructed a walking-beam engine, with which they drove a printing press, using a zinc and copper battery, with a soluth of blue vitriol as the exciting liquid.

In 1842 Davidson, of Scotland, constructed a five-ton four miles per hour with seventy-eight pairs of zine and iron in sulphuric acid solution, the plates being thirteen inches square.

an electro-magnet in conceived the idea of substituting net in the magneto-electric machine of Pixii, and the further idea of using this electro-magneto electric mato excite the field magnets of a still larger electro(This idea was machine

This idea was subsequently, in 1863-6, further elabIn $1847^{7}$ I constructed and exhibited in public an ele tro-magnetic locomotive, and with forty-eight pint-cup cells of Grove nitric acid battery drew a little car carry-
ing two passengers on a track a foot and a half wide. magnetic engine of sixteen horse-power, and with a
hundred cells of Grove nitric acid battery, each having platinum plates eleven inches square, he propelled a car carrying a dozen or more passengers on the Washington and Baltimore Railroad at the rate of nineteen
miles per hour. miles per hour. Daniel Davis), constructed, and later exhibited at the locomotive which took its current from a stationary
battery by means of the rails and wheel, as the followbattery by means of the rails and wheel, as the following extract from a letter written to me by him, November 25 , will show : " In the year 1851, when I was at
work for Daniel Davis, I made a small electric locomolong. The wheels were insulated, and the electricity was conveyed to the engine by means of the rails from two Grove batteries. The cut-off was in the engine, and worked automatically or by hand, so that when
the engine reached the end of the track the switch reversed the engine, and it went back to the starting point. finished, which ran on a circular track about eight feet in diameter. The current was conducted to the insurails. I have a part of one of these engines on hand ow, and photographs of the Volta ; also woodcuts of ween 1851 and 1860 ." I asked Mr. Hall's permission to publish his letter and in reply he says: " Shall be glad to have you publish the facts as I have stated them to you, and shall be obliged to you for doing it. You know they are These four engines, therefore, of Davidson, Farmer, Page, and Hall could be started and stopped, sent forIn 1859 I conceived of the self-exciting dynamo, which I constructed in 1866, and which was also conceived of by Wheatstone, Siemens, and Ladd in 1867 and by Gramme in 1871 , so that by 1871 cheap electricity becubstitute the dynamo machine for the galvanic batsubstitute the dynamo machine for the galvanic bat-
tery to make electro-locomotion both possible and or more. tuting the now well-known dynamo for the more expensive and troublesome acid battery, appear to be ust on the eve of bringing to blossom and fruitage those buds of pronise after their long forty years of germation, because there was then no
elevated and so they came not forth.

There are two principal methods of propelling an lectricity, such as a galvanic battery, as did David son's, Farmer's, and Page's. 2d. It is picked up from a did Hall's source by means of the wheels and rails, a In the later days, since the advent of the storage batried on a tender, and it is worthy of very patient and long experimental inquiry, wlich method is the cheaper ive, or to charge the storage battery, place it on tender, and attach it to the locomotive.

Bx the addition of ten parts of collodion to fifteen orained which is more con layed teeth than is creosote in its liquid form.
ELECTRICAL SPEED INDICATORS.

OUR illustrations represent Messrs. Farquharson and Lane's patent electrical speed indicator, specially de-
signed for use on board ship for indicating the number of revolutions per minute at which an engine is running. f course there are a number of other uses to which this strument may be applied, such as checking the speed The design of the instrument is certainly novel, and,
, rom its simplicity, compactness, and reliability, should A small commutator is fixed upon the shaft of the ngine or other piece of machinery, the speed of which is required to note, and upon this a contact brush is made to bear. The commutator is so arranged that at
each revolution of the shaft one contact only for an

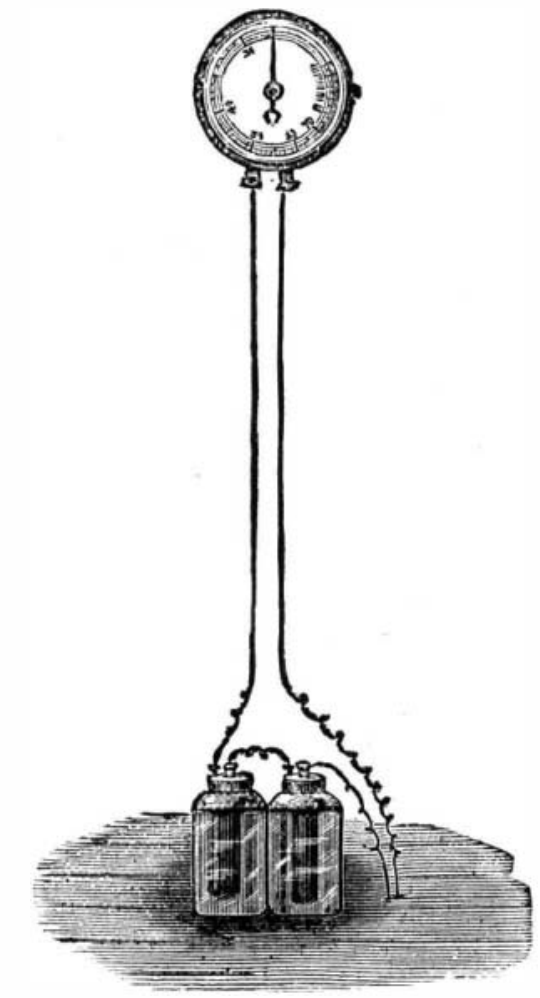

nstant is made; the shaft is in connection with one to arth. The contact brush is joined by means of an
nsulated wire to the indicator, and from thence to

It is evident that with a shaft traveling a given umber of revolutions per minute, the interval of tim tion of the commutator against the brush would be a constant interval, its length being in accordance with the speeds.

The indicator is so constructed that by pressing a plete the instant the commutator on the shaft has come contact with the rubbing brush. By means of an stant the circuit is completed the pointer is released and continues to move around the dial until the com-
mutator on the shaft has again come in contact with the

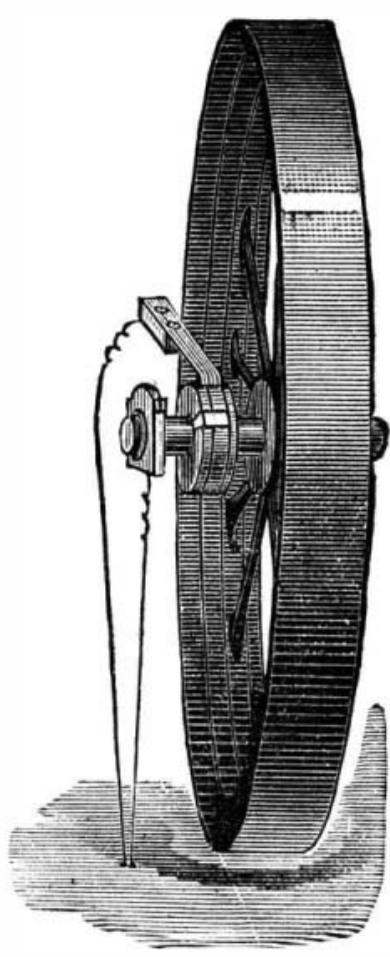

brush and completed the circuit a second time this moment the pointer will be instantaneously stopped. follows that the interval of time taken for the han volution of the shaft, and if, therefore, instead of marking the number of seconds or parts of seconds corresponding to that interval of time, it follows that the speed of the shaft may be indicated. For instance 列 revolutions per minute, it would take one second to time would have traveled a certain distance around represent the number of revolutions of the shaft pe 